\title{
Article \\ Salicylic-Acid-Regulated Antioxidant Capacity Contributes to Growth Improvement of Okra (Abelmoschus esculentus cv. Red Balady)
}

Sabry M. Youssef ${ }^{1}\left(\mathbb{D}\right.$, Antonio López-Orenes ${ }^{2}$, María A. Ferrer ${ }^{2, *}$ (D) and Antonio A. Calderón ${ }^{2}$

Citation: Youssef, S.M.;

López-Orenes, A.; Ferrer, M.A.;

Calderón, A.A.

Salicylic-Acid-Regulated Antioxidant

Capacity Contributes to Growth

Improvement of Okra (Abelmoschus

esculentus cv. Red Balady). Agronomy

2022, 12, 168. https://doi.org/

10.3390/agronomy12010168

Received: 9 December 2021

Accepted: 7 January 2022

Published: 10 January 2022

Publisher's Note: MDPI stays neutral with regard to jurisdictional claims in published maps and institutional affiliations.

Copyright: (C) 2022 by the authors. Licensee MDPI, Basel, Switzerland. This article is an open access article distributed under the terms and conditions of the Creative Commons Attribution (CC BY) license (https:// creativecommons.org/licenses/by/ $4.0 /)$.
1 Horticulture Department, Faculty of Agriculture, University of Ain Shams, Cairo 11241, Egypt; sabrysoliman@hotmail.com

2 Departmento de Ingeniería Agronómica, Universidad Politécnica de Cartagena, Paseo Alfonso XIII 48, 30203 Cartagena, Spain; antonio_lopez_orenes@hotmail.com (A.L.-O.); antonio.calderon@upct.es (A.A.C.)

* Correspondence: mangeles.ferrer@upct.es

\begin{abstract}
The improvement of crop yield and quality are currently of prime concern to achieve global food security and sustainability. Plant elicitation with salicylic acid (SA) has been shown to play a key role in regulating plant growth and productivity. Here, the effects of foliar SA application (1, 2, and $4 \mathrm{mM}$ ) on antioxidant capacity and phenolic metabolism, among other biochemical parameters, were studied in okra leaves. The results showed that SA treatments markedly increase the levels of endogenous free SA and trigger the accumulation of chlorophylls, soluble proteins, proline, antioxidant capacity, and phenolic compounds, alongside the stimulation of the enzymatic activities of phenylalanine ammonia-lyase and peroxidase, with these changes being paralleled by decreased levels of lipid peroxidation. The beneficial effects of SA treatments were also tested on field-grown okra plants. Results revealed that yield-associated agronomic attributes significantly increased upon SA treatments, especially at $2 \mathrm{mM} \mathrm{SA}$. Altogether, these results point to a connection between SA-induced antioxidant system strengthening and crop growth and productivity. Therefore, foliar application of SA seems to be a potent and workable approach to enhance okra crop quality and yield.
\end{abstract}

Keywords: antioxidant compounds; crop yield; elicitation; okra; phenol metabolism; salicylic acid

\section{Introduction}

Okra (Abelmoschus esculentus (L.) Moench), also known as lady's fingers, gumbo, bhindi, or bamya, is an important warm-season, fast-growing, annual crop of the mallow family. Very recently, it has been included in the top-50 food list due to its nutritional and nutraceutical properties [1,2]. Abelmoschus esculentus is an ancient crop of African origin, mostly cultivated within tropical and subtropical regions worldwide for its immature pods and tender leaves, which are consumed as vegetables [2,3]. Okra pods have also been used in traditional medicine to treat diarrhea, dysentery, and urinary infections [4]. Nevertheless, not only the pods and leaves, but the whole plant can be used for several food, medical, and industrial purposes, including food thickening, paper pulp, bioflocculation, and biofuel production $[3,5,6]$.

Worldwide, okra production is around $9.9 \mathrm{Mt}$, with more than $74 \%$ of its production concentrated in low-income, food-deficit countries (LIFDCs), although the LIFDCs' average yield is half that found in the European Union [7]. Therefore, the implementation of costeffective strategies aimed at boosting okra yield as well as its nutritional and nutraceutical values is of great interest. Currently, the use of chemical priming is considered an important tool to improve crop quality and to mitigate the effects of environmental stress in plants at a minimal fitness cost [8]. Accumulating evidences demonstrated that the use of low concentrations of phytohormones can prime plant stress tolerance [9]. In particular, the phenolic 
phytohormone salicylic acid (SA), which is synthetized through phenylalanine or isochorismate [10], is known to influence several developmental processes such as seed germination, vegetative growth, senescence, flower formation, and fruit yield [11]. Moreover, SA plays a crucial signaling role in plant defense responses against both pathogens [10,12] and abiotic stress factors [13]. SA has been used to promote the accumulation of a broad spectrum of defense-related proteins and metabolites and to alleviate plant damage caused by environmental factors [13]. Thus, exogenous application of SA has been found to influence a range of diverse physiological processes in plants, including photosynthetic and growth rates [14,15], membrane permeability and mineral uptake [16], and redox potential and cell homeostasis [17] as well as the accumulation of bioactive secondary metabolites [13,18-22]. On the other hand, recent epidemiological studies reported that antioxidant secondary metabolites, particularly phenolics, exert protective effects against oxidation-linked chronic human diseases, due to their ability to modulate epigenetic mechanisms, including DNA methylation, histone modifications, and microRNA expression [23,24].

However, no information is available about the effect of the SA applications on okra in terms of nutritional quality, growth, and crop overall performance. Therefore, this study was conducted to evaluate the effect of foliar application of SA at low doses $(0,1,2$, and $4 \mathrm{mM}$ ) on growth attributes, antioxidant capacity, and phenol metabolism in the leaves of okra plants grown under controlled conditions. The effects of these SA doses were also evaluated in SA-sprayed plants under field conditions in order to verify the extent to which the selected SA treatments affect agronomic and fruit yield.

\section{Materials and Methods}

\subsection{Plant Material and Culture Conditions}

The plant material used in this study was the okra cultivar Red Balady, which has been estimated to cover almost $70 \%$ of the total okra cultivated area ( $>4300$ hectares in the agriculture year 2018/19 [25]) in Egypt. Seeds of okra were surface sterilized with $95 \%$ ethanol for 3 min and then with $20 \%(v / v)$ Domestos ${ }^{\circledR}(4.3 \%$ sodium hypochlorite, Unilever, UK) for five min with shaking and thoroughly washed with sterile distilled water $\left(\mathrm{dH}_{2} \mathrm{O}\right)$. The seeds were pre-soaked in $\mathrm{dH}_{2} \mathrm{O}$ for 1 day and kept in the dark for 3 days to induce germination. Uniformly germinated seeds were then transferred to $24 \mathrm{~L}$ plastic pots $(30 \mathrm{~cm}$ in diameter and $35 \mathrm{~cm}$ in depth) filled with a mixture of peat moss and perlite $(2: 1, v / v)$ and randomly divided into four groups to give a total of 48 pots (12 pots per treatment). Seedlings were grown in a plastic tunnel under a $12 \mathrm{~h}$ photoperiod provided by LED panels (red:blue:white:yellow:UV-A = 7.15:1.45:0.7:0.35:0.35) at a PAR of $1300 \mu \mathrm{mol} \mathrm{m} \mathrm{m}^{-2} \mathrm{~s}^{-1}$, with $30 / 25^{\circ} \mathrm{C}$ day/night temperatures and relative humidity of $75 \% \pm 5 \%$. Plants were watered with Hoagland's nutrient solution [26] weekly. Three weeks after sowing (at the three-leaf stage), okra plants were sprayed with a hand sprayer (250 mL per plant) with different SA concentrations $(1,2$, and $4 \mathrm{mM}$ ) twice separated by a two-week interval. SA (Sigma-Aldrich purity $>99 \%$ ) was initially dissolved in ethanol and then diluted with Milli-Q water (ethanol/water: 1/1000, $v / v$ ). The $\mathrm{pH}$ of all solutions was adjusted to 6.5 using $3 \mathrm{mM}$ Mes $/ \mathrm{KOH}$ [20]. A control group of plants was sprayed with ethanol/water $(1 / 1000, v / v)$. At 45 days after sowing, fresh fully expanded leaves from eight plants of each treatment were collected, randomly divided into four groups and immediately flash frozen in liquid nitrogen, cryogenically pulverized in a liquid nitrogen-cooled analytical mill (IKA, Labortechnik, Staufen, Germany), and stored at $-80{ }^{\circ} \mathrm{C}$ for further biochemical analysis. The experiment was repeated twice and arranged in a randomized complete block.

In addition, okra seeds were grown on planting beds at a distance of $60 \mathrm{~cm}$ between rows and $40 \mathrm{~cm}$ between plants in a row (12 plants per row). Each experimental plot was composed of five, $5 \mathrm{~m}$ long rows. The experiment was conducted in a randomized complete block design (RCBD) with three replications for each treatment. All the cultural practices were carried out uniformly in all plots as recommended for okra production [27]. This experiment was carried out during the summer seasons of 2013 and 2014 in the 
experimental farm of the Ain Shams University $\left(30^{\circ} 06^{\prime} 47^{\prime \prime} \mathrm{N}, 31^{\circ} 14^{\prime} 37^{\prime \prime} \mathrm{E}\right)$. Three weeks after sowing, okra plants were sprayed with different SA doses as previously mentioned.

\subsection{Chlorophyll Quantification}

The extraction and quantification of chlorophylls were performed as previously described [28]. In short, liquid nitrogen-powdered leaf samples $(\sim 0.1 \mathrm{~g})$ were extracted with $100 \%$ methanol $(1.0 \mathrm{~mL})$ using sonication at $40{ }^{\circ} \mathrm{C}$ for 30 min repeatedly until the extract became colorless. After centrifugation $\left(15,000 \times g\right.$ for $15 \mathrm{~min}$ at $\left.4{ }^{\circ} \mathrm{C}\right)$, the absorbance of the collected supernatants was read at 666, 653, and $470 \mathrm{~nm}$ in a 96-well plate reader (Multiskan GO, Thermo Scientific, Waltham, MA, USA) to calculate the content of chlorophyll a (Chl a) and $\mathrm{b}(\mathrm{Chl} \mathrm{b}$ ) according to the equations proposed by Lichtenthaler and Wellburn [29]. The chlorophyll contents were expressed in micrograms per gram of fresh weight ( $\left.\mu \mathrm{g} \mathrm{g}^{-1} \mathrm{FW}\right)$.

\subsection{Determination of Proline and Lipid Peroxidation}

For proline determination, about $0.1 \mathrm{~g}$ of liquid nitrogen-powdered leaf samples were homogenized in $1 \mathrm{~mL}$ of $3 \%$ sulfosalicylic acid $(w / v)$. After centrifugation at $12,000 \times g$ for $10 \mathrm{~min}$, the supernatants were collected and used for the analysis of proline by the ninhydrin reagent method, as previously described [28]. The proline contents were expressed as $\mu \mathrm{mol} \mathrm{g}{ }^{-1} \mathrm{FW}$.

The lipid peroxidation level was assayed by measuring the formation of malondialdehyde (MDA) using the thiobarbituric acid reactive method [28]. The MDA concentration was calculated using an extinction coefficient of $155 \mathrm{mM}^{-1} \mathrm{~cm}^{-1}$. The degree of lipid peroxidation in okra leaves was expressed as $\mu \mathrm{mol}$ of $\mathrm{MDA} \mathrm{g}^{-1} \mathrm{FW}$.

\subsection{Determination of Total Antioxidant Activity and Phenolic Compounds}

The determination of the total antioxidant capacity (TAC) was carried out using leaf methanolic extracts $[21,28]$. In short, methanolic extracts $(20 \mu \mathrm{L})$ were used to determine their ability to scavenge the $\mathrm{DPPH}^{\bullet}\left(2,2\right.$-diphenyl-1-picrylhydrazyl), and $\mathrm{ABTS}^{\bullet+}$ radicals, and to reduce $\mathrm{Fe}(\mathrm{III})$ to $\mathrm{Fe}(\mathrm{II})$ using the ferric-reducing antioxidant power (FRAP) assay. The antioxidant capacity was expressed as $\mu \mathrm{mol}$ of reduced $\mathrm{ABTS}^{\bullet+}$ or $\mathrm{DPPH}^{\bullet}$ as gallic acid or Trolox equivalents per gram fresh weight. The ferric reducing antioxidant power of the leaf extracts was expressed as $\mu \mathrm{mol} F($ III) per gram fresh weight.

The quantification of phenolic compounds in leaf methanolic extracts was performed according to [28]. Briefly, the total soluble phenol content (TPC) was determined by the Folin-Ciocalteu method using gallic acid $(0-1000 \mu \mathrm{M})$ as the standard. Total soluble phenol content was expressed as gallic acid equivalents (GAEs) per gram fresh weight. The total flavonoid content (TFC) was determined by using the aluminum chloride method, and TFC was reported as total rutin equivalents per gram fresh weight. The flavanol content was determined spectrophotometrically with DMACA ( $p$-dimethylaminocinnamaldehyde) reagent, using (+)-catechin $(0-500 \mu \mathrm{M})$ as the standard, according to [30]. Flavanol content was expressed as catechin equivalents per gram fresh weight. The hydroxycinnamic acid content (HCA) was determined by using Arnow's reagent. Briefly, $25 \mu \mathrm{L}$ of each sample or caffeic acid standard solution $(0-3000 \mu \mathrm{M})$ was mixed with $50 \mu \mathrm{L}$ of $1.5 \mathrm{~N} \mathrm{HCl}$, followed by addition of $50 \mu \mathrm{L}$ of a $10 \%(w / v)$ sodium nitrite solution. Then, $50 \mu \mathrm{L}$ of $10 \% \mathrm{Na}_{2} \mathrm{MoO}_{4}$ $2 \mathrm{H}_{2} \mathrm{O}, 50 \mu \mathrm{L}$ of $2 \mathrm{~N} \mathrm{NaOH}$, and $25 \mu \mathrm{L}$ of distilled water were added, and the mixture was mixed well. The absorbance was immediately measured at $525 \mathrm{~nm}$. HCA was expressed as caffeic acid equivalents per gram fresh weight.

\subsection{Extraction and Quantification of $S A$}

Free SA was quantified by using the SA biosensor strain Acinetobacter sp. ADPWH_lux [31,32] with some modifications [33]. In short, frozen leaves $(\sim 0.1 \mathrm{~g})$ were homogenized in $250 \mu \mathrm{L}$ of sodium acetate buffer ( $0.1 \mathrm{M}, \mathrm{pH}$ 5.6), and centrifuged for $15 \mathrm{~min}$ at 16,000 $\times$ g. An overnight culture of Acinetobacter sp. ADPWH_lux was diluted in LB (1:20) and grown for $3 \mathrm{~h}$ at $200 \mathrm{rpm}$ to an $\mathrm{OD}_{600}$ of 0.4 . Twenty microliters of leaf supernatants was 
added to an optiplate (Falcon Optilux 96-well plate) containing $60 \mu \mathrm{L}$ LB. Following this, $50 \mu \mathrm{L}$ of biosensor culture was added to each well simultaneously using a multi-pipette and mixed by pipette action. The plate was incubated at $37^{\circ} \mathrm{C}$ for $1 \mathrm{~h}$ before luminescence signals were captured using a Fusion FX7 detection system and quantified with Bio1D software (Vilber Lourmat, France). Known amounts of SA were used as standards. SA standards were read in parallel with the experimental samples. Conversion of luminescence to SA concentration was done using the standard curve and results were expressed as $\mu \mathrm{g}$ SA per gram fresh weight.

\subsection{Enzymatic Assays}

For the extraction and assay of phenylalanine ammonia-lyase (PAL, EC 4.3.1.24) and peroxidase (Prx, EC 1.11.1.7) enzymatic activities, about $0.3 \mathrm{~g}$ of liquid nitrogen-powdered leaves were homogenized at $4{ }^{\circ} \mathrm{C}$ in cold extraction buffer $(50 \mathrm{mM}$ Tris- $\mathrm{HCl}, \mathrm{pH} 8.8,5 \mathrm{mM}$ ethylenediamine tetra-acetic acid (EDTA), $5 \mathrm{mM}$ ascorbic acid, $1 \mathrm{mM}$ phenylmethylsulfonyl fluoride (PMSF), $0.1 \%(w / v)$ Triton X-100, $200 \mu \mathrm{M}$ dithiothreitol (DTT), and $0.25 \%$ $(w / v)$ polyvinylpolypyrrolidone). The homogenates were centrifuged $(48,000 \times g, 30 \mathrm{~min}$, $\left.4{ }^{\circ} \mathrm{C}\right)$ and the supernatants $(2.5 \mathrm{~mL})$ were then desalted by chromatography on PD-10 Sephadex G-25 columns (GE Healthcare, Buckinghamshire, UK), equilibrated either with $25 \mathrm{mM}$ Tris- $\mathrm{HCl}$ (pH 8.8) containing $1 \mathrm{mM}$ EDTA to determine PAL activity, or with $25 \mathrm{mM}$ sodium acetate, $\mathrm{pH} 5.5$ to determine Prx activity. PAL activity was determined spectrophotometrically by following the conversion of L-phenylalanine into trans-cinnamic acid $\left(\varepsilon_{290}=9.5 \mathrm{mM}^{-1} \mathrm{~cm}^{-1}\right)$ [28]. Prx activity was estimated by following the oxidation of $0.1 \mathrm{mg} \mathrm{mL}^{-1}$ tetramethylbenzidine- $\mathrm{HCl}\left(\varepsilon_{652}=39 \mathrm{mM}^{-1} \mathrm{~cm}^{-1}\right)$ at $652 \mathrm{~nm}$ for $1 \mathrm{~min}$ in a reaction medium containing $50 \mathrm{mM}$ sodium acetate $\left(\mathrm{pH}\right.$ 5.5) and $1 \mathrm{mM} \mathrm{H}_{2} \mathrm{O}_{2}$.

The protein concentrations were determined by using the Bradford protein assay kit (Bio-Rad Laboratories) and bovine serum albumin (BSA) as standard.

\subsection{Agronomic and Fruit Quality Determinations}

At 45 days after planting, 10 plants in the middle rows were randomly selected from each plot to prevent border effect and tagged for data collection. The growth parameters measured were as follows: plant height, number of branches per plant, girth of main stem, number of leaves per plant, leaf area, and fresh and dry weight of vegetative growth.

In addition, the total foliar N, P, and $\mathrm{K}$ contents were determined by the Kjeldahl, molybdate-ascorbic acid, and flame photometric methods, respectively, using standard protocols as described in the literature [34]. For elemental analysis, a fine powder of ovendried leaf samples $(\sim 0.1 \mathrm{~g})$ was digested using a mixture of sulfuric acid $(98 \%$, Merck Emsure) and hydrogen peroxide (30\%, Merck, Suprapur). Leaf relative water content (LRWC) was also determined [35] as well as the leaf membrane stability index (LMSI) [36]. In short, for LMSI measurement, leaf disks were washed with double-distilled water $\left(\mathrm{ddH}_{2} \mathrm{O}\right)$ and placed in vials with $10 \mathrm{~mL}$ of $\mathrm{ddH}_{2} \mathrm{O}$ in two sets. One set was kept at $30{ }^{\circ} \mathrm{C}$ in a water bath for $30 \mathrm{~min}$, and then, the electrical conductivity (EC1) was measured. The electrical conductivity of the second set (EC2) was determined after an incubation period of $15 \mathrm{~min}$ at $100{ }^{\circ} \mathrm{C}$. LMSI was calculated according to the following formula: LMSI $=(1-(\mathrm{EC} 1 / \mathrm{EC} 2)) \times 100$.

The yield and biometric traits of okra fruits were also determined. The marketable fruits were harvested at 2-3 day intervals and measured for overall yield (number of fruits per plant, fruit yield per plant, and fruit yield per hectare), as well as average fruit weight, and length.

\subsection{Statistical Analysis}

The statistical analysis of pot and field data was conducted using the SPSS package program (version 26.0; SPSS Inc., Chicago, IL, USA). Data were analyzed using one-way analysis of variance (ANOVA) with SA treatment as a fixed factor. The differences among 
means of data were compared by Tukey's HSD post hoc test. All statistical determinations were made at $p \leq 0.05$.

Principal component analysis (PCA) was also performed using the CANOCO for Windows program v4.02. Prior to PCA, raw data were $\log (x+1)$ transformed and median centered.

\section{Results}

\subsection{Effect of SA Treatments on Chlorophylls, Protein, and SA Contents}

In okra plants, foliar SA treatments significantly increased chlorophyll a and b contents in a dose-dependent manner, with the maximal effect obtained (>2.2-fold) at the 4 mM SA concentration in comparison with the controls (Figure 1a,b). Moreover, the concentration of soluble protein in SA-treated plants also increased and followed a bell-shaped curve, with maximum values obtained with SA at $2.0 \mathrm{mM}$ ( 2.3-fold) (Figure 1c).
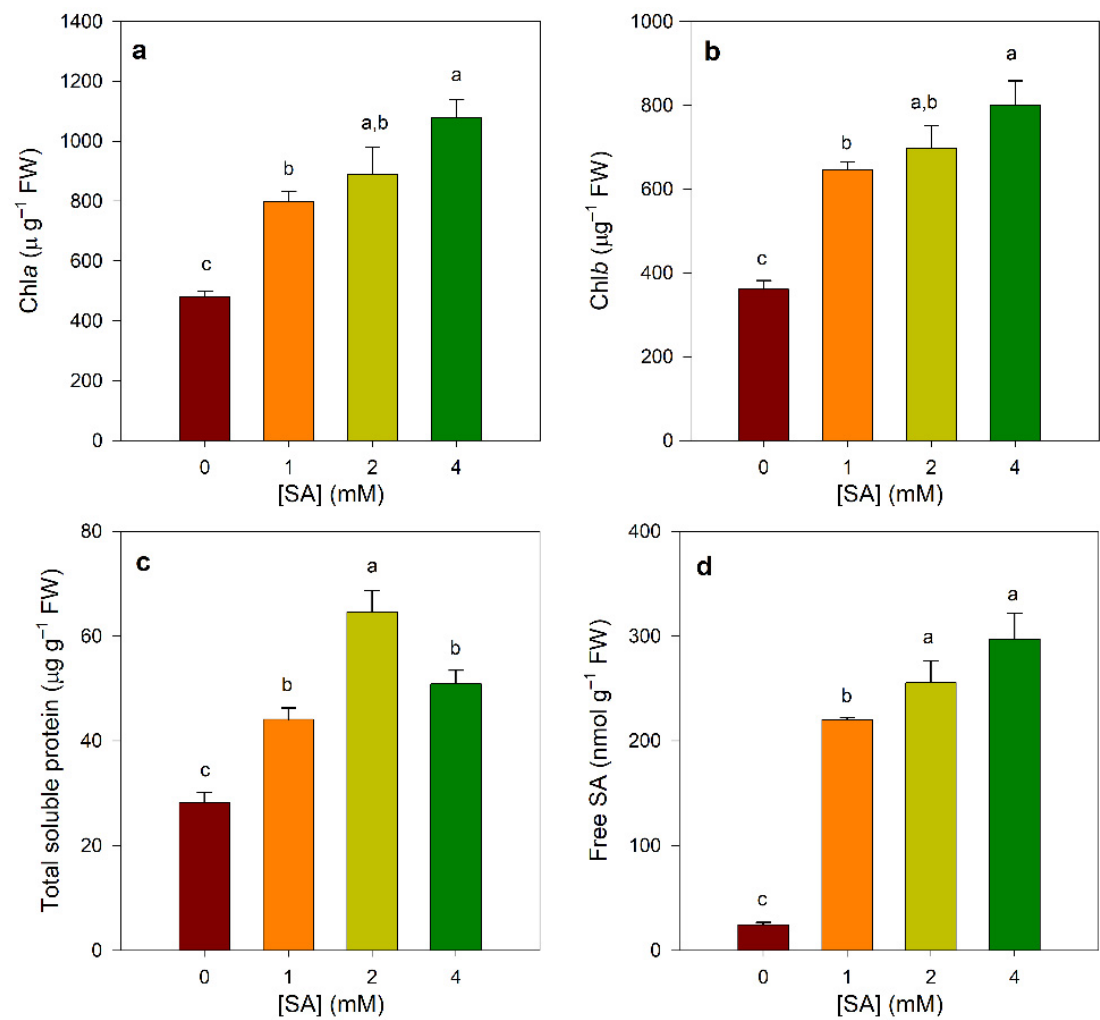

Figure 1. Effect of foliar SA application on chlorophylls (a,b), total soluble proteins (c), and endogenous SA levels (d) in leaves of 45-day-old okra plants. The data are means \pm SE from $n=16$ from two experiments. Different letters indicate significant difference at $p \leq 0.05$ (Tukey's HSD post hoc test). $F$-values and level of significance from ANOVA: chla, $18.54^{* * *}$; chlb, $20.33^{* * *}$; total soluble proteins, $13.32^{* * *}$; and SA, $2667.72^{* * *}(* * * 00.001)$.

To quantify SA levels, we used the SA-biosensor-based luminescence method, which has been shown to have an accuracy comparable to that of GC-MS [33]. The analysis of SA accumulation in leaves showed a notorious increase in SA levels ( 10-fold), particularly in plants treated with SA at both 2 and $4 \mathrm{mM}$ in comparison to controls (Figure 1d). Furthermore, there was a strong correlation between free endogenous SA contents and both chlorophyll $(\mathrm{r}>0.8, p \leq 0.01)$ and protein levels $(\mathrm{r}>0.6, p \leq 0.01)$ (Supplementary Table S1) in okra leaves.

\subsection{Effect of SA Treatments on Proline and MDA Contents}

In order to verify to what extent SA applications provoke cellular damage, the level of malondialdehyde (MDA) as an index of lipid peroxidation and the levels of proline, 
a well-known stress-metabolite, were measured. As shown in Figure 2a, the exogenous application of SA at 2.0 and $4.0 \mathrm{mM}$ significantly reduced the accumulation of MDA levels in okra leaves $(\sim 40 \%$ and $20 \%$, respectively). No pronounced changes were noted in $1.0 \mathrm{mM}$ SA-treated plants compared with the controls.
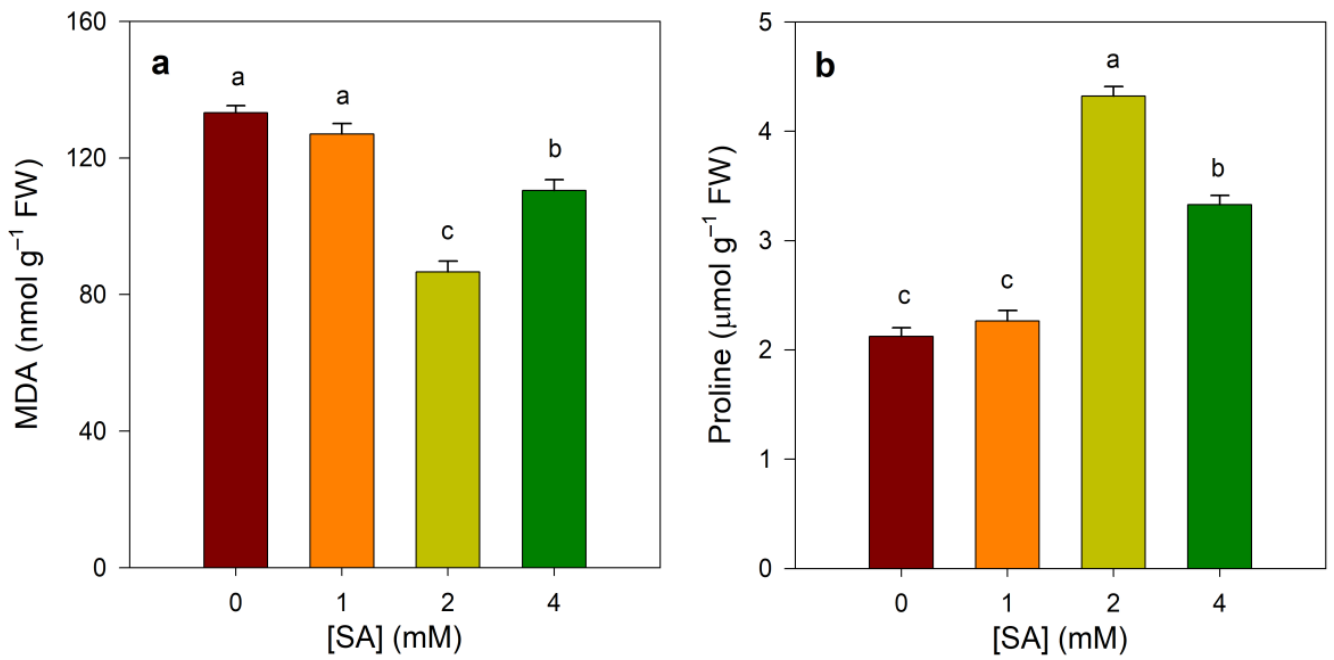

Figure 2. Effect of foliar SA applications on lipid peroxidation (a) and proline levels (b) in leaves of 45-day-old okra plants. The data are means \pm SE from $n=16$ from two experiments. Different letters indicate significant difference at $p \leq 0.05$ (Tukey's HSD post hoc test). F-values and level of significance from ANOVA: MDA, $52.43^{* * *}$; Pro, $3901.66^{* * *}\left({ }^{* * *} p \leq 0.001\right)$.

Contrarily, SA treatment provoked a marked increase in proline contents in okra leaves, especially at $2 \mathrm{mM}$ of SA ( 2.0-fold), and to a lesser extent at $4 \mathrm{mM} \mathrm{SA}(\sim 1.5$-fold), whereas their levels remained unchanged in $1 \mathrm{mMSA}$-treated plants with regard to controls (Figure 2b).

\subsection{Effect of SA Treatments on Total Antioxidant Capacity and Phenolic Contents}

To study the effects of SA treatments on the antioxidant properties of okra leaves, we evaluated their total antioxidant capacity (TAC) by measuring the ability of leaf methanolic extracts to scavenge the radicals $\mathrm{ABTS}^{\bullet+}$ and $\mathrm{DPPH}^{\bullet}$ as well as to reduce Fe(III) to Fe(II) by the FRAP assay. As shown in Figure 3 and Supplementary Figure S1, foliar application of $\mathrm{SA}$, irrespective of the concentration, resulted in significant increases in total antioxidant capacities as compared with control, particularly in the plants sprayed with $2 \mathrm{mM} \mathrm{SA}$. However, there were no significant statistical differences between plants treated with 2 and $4 \mathrm{mM}$ in both DPPH-radical scavenging and FRAP assays. In addition, strong correlations were found between endogenous SA content and both FRAP ( $\mathrm{r}>0.95, p \leq 0.01)$ and radical scavenging assays $(r>0.82, p \leq 0.01)$ (Supplementary Table S1).

The data in Figure $3 \mathrm{~d}-\mathrm{g}$ clearly showed that SA treatments significantly increased total soluble phenol, flavonoid, flavanol, and hydroxycinnamic acid contents in the leaves of okra. However, there were differences in the trend of increase among these phenolic groups. Thus, the highest values of TPC and TFC were obtained at both 2 and $4 \mathrm{mM}$ of SA ( 1.7and 1.2-fold, respectively), whereas $4 \mathrm{mM}$ of SA was the most effective in increasing HCA ( 1.4-fold). However, the increases in flavanol content as compared to controls at different concentrations of SA were not statistically significant (Figure 3f). Strong correlations were also seen between endogenous SA levels and TPC $(r>0.75, p \leq 0.01)$ and the content of specific phenolic groups $(\mathrm{r}>0.8, p \leq 0.01)$ (Supplementary Table S1). 

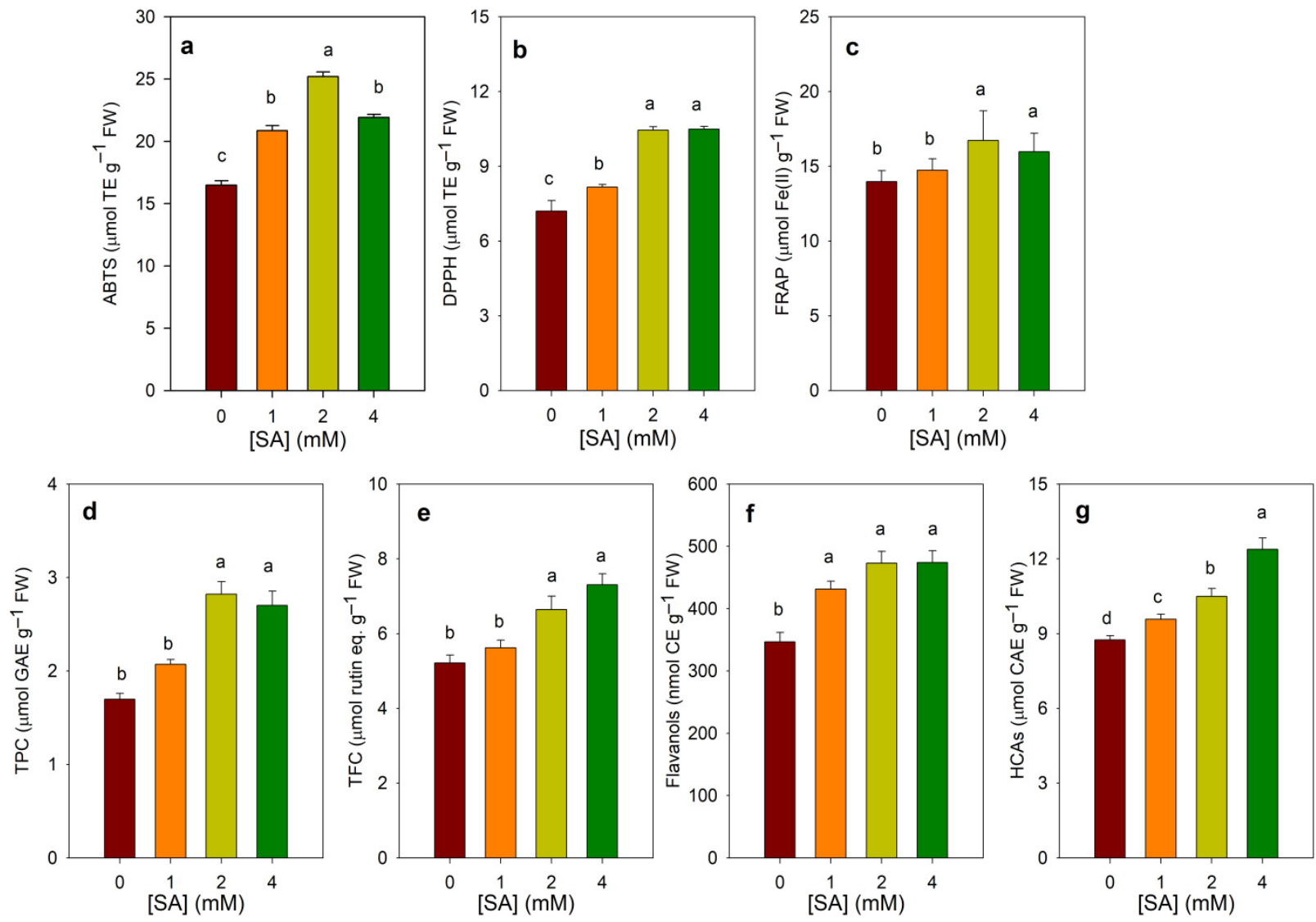

Figure 3. Effect of foliar SA applications on total antioxidant activities (a-c), and phenolic contents (d-g) in leaves of 45-day-old okra plants. (a) $\mathrm{ABTS}^{\bullet+}$ - radical scavenging activity; (b) $\mathrm{DPPH}^{\bullet}$-radical scavenging activity; (c) FRAP; (d) total phenol content; (e) total flavonoid content; (f) flavanols; (g) hydroxycinnamic acid content. The data are means \pm SE from $n=16$ from two experiments. Different letters indicate significant difference at $p \leq 0.05$ (Tukey's HSD post hoc test). F-values and level of significance from ANOVA: ABTS, $107.95^{* * *}$; DPPH, $50.02^{* * *}$; FRAP, $269.27^{* * *}$; TPC, $22.87^{* * *}$; TFC, $543.63^{* * *}$; flavanols, $17.55^{* * *}$; and HCAs, $\left.352.3^{* * * * * *} p \leq 0.001\right)$.

\subsection{Effect of SA Treatments on PAL and Prx Activities}

The behavior of PAL and class III peroxidases (Prxs) were also analyzed since they are representative enzymes involved in shaping the phenolic profile in plants. As shown in Figure 4a, PAL enzymatic activities displayed a bell-shaped curve in SA-treated plants, with maximum values obtained with SA at $2 \mathrm{mM}$ (>2-fold). Concerning Prx activity, foliar application of SA, irrespective of the concentration, caused a statistically significant increase in Prx activity as compared with controls (Figure 4 b). Nevertheless, there was a trend of decrease of Prx activity levels as the exogenous SA dose increased. 

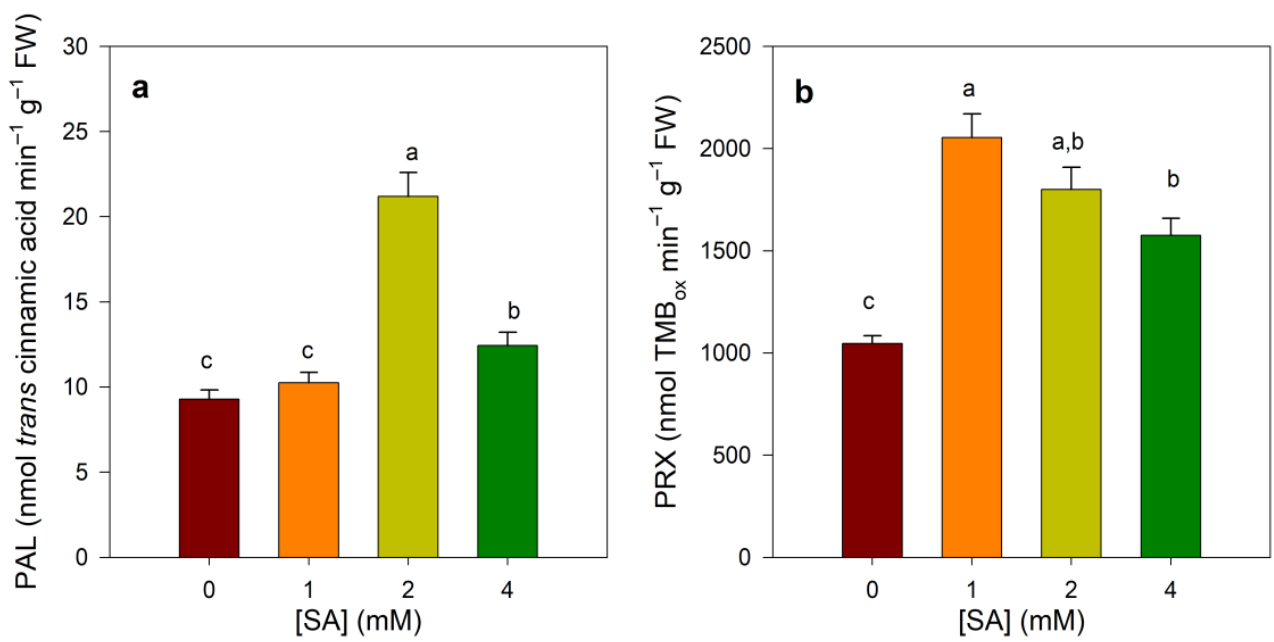

Figure 4. Effect of foliar SA applications on PAL (a) and Prx (b) activities in leaves of 45-day-old okra plants. The data are means \pm SE from $n=16$ from two experiments. Different letters indicate significant difference at $p<0.05$ (Tukey's HSD post hoc test). $F$-values and level of significance from ANOVA: PAL, 501.27**; and Prx, $22.30^{* * *}\left(^{* * *} p \leq 0.001\right)$.

\subsection{Effect of SA Treatments on Agronomic Traits}

The impact of SA foliar application on the performance of okra plants grown under field conditions in two consecutive summer-growing seasons was also studied. As can be seen in Figure 5, both vegetative growth parameters and fruit quality biometric traits tend to increase in plants treated with $2 \mathrm{mM}$ of SA in comparison to controls (see also Supplementary Tables S2 and S3). Thus, 2 mM SA-treated plants showed higher number of leaves per plant ( 1.4-fold) as well as greater fresh and dry vegetative biomass ( $\sim$ 1.4-fold) compared to control plants. Moreover, the higher content in N, P, and $\mathrm{K}$ found in leaves from 2 mM SA-treated plants ( 1.2-, 1.4-, and 1.6-fold, respectively) showed good correlations with the number of leaves and vegetative plant biomass $(r>0.6, p \leq 0.01)$, as well as with fruit yield parameters $(\mathrm{r}>0.5, p \leq 0.01)$. Furthermore, high-to-moderate correlations were found between MSI with both vegetative plant biomass $(r>0.7, p \leq 0.01)$ and fruit yield parameters $(\mathrm{r}>0.6, p \leq 0.01)$ (Supplementary Table S4).

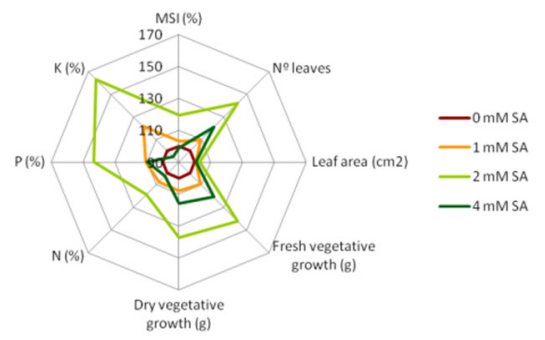

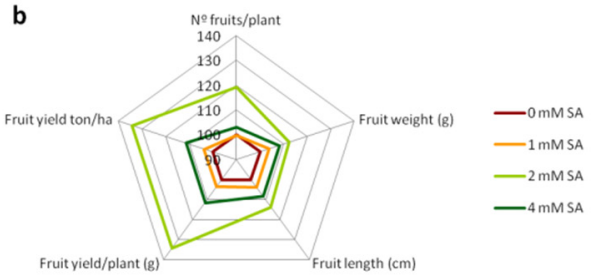

Figure 5. Effect of foliar SA applications on agronomic vegetative growth parameters (a) and fruityield-related attributes (b). Data are expressed as percentage of the corresponding control value in the absence of SA treatment. For means \pm SE values and statistical analysis see Supplementary Table S3.

\subsection{Principal Component Analyses}

Principal component analyses were carried out in order to determine to what extent foliar SA treatment affected antioxidant and phenolic profiles as well as agronomic yield parameters (Figure 6). As regards biochemical parameters, PCA1, which accounted for $66.6 \%$ of the variation, discriminated between controls and SA-treated plants as well as between 1 and $4 \mathrm{mM} \mathrm{SA}$-treated plants, whereas PCA2, which accounted for $12.6 \%$ of the variation, allowed discrimination between $2 \mathrm{mM} \mathrm{SA}$-treated plants and the other SA treatments (Figure 6a). 

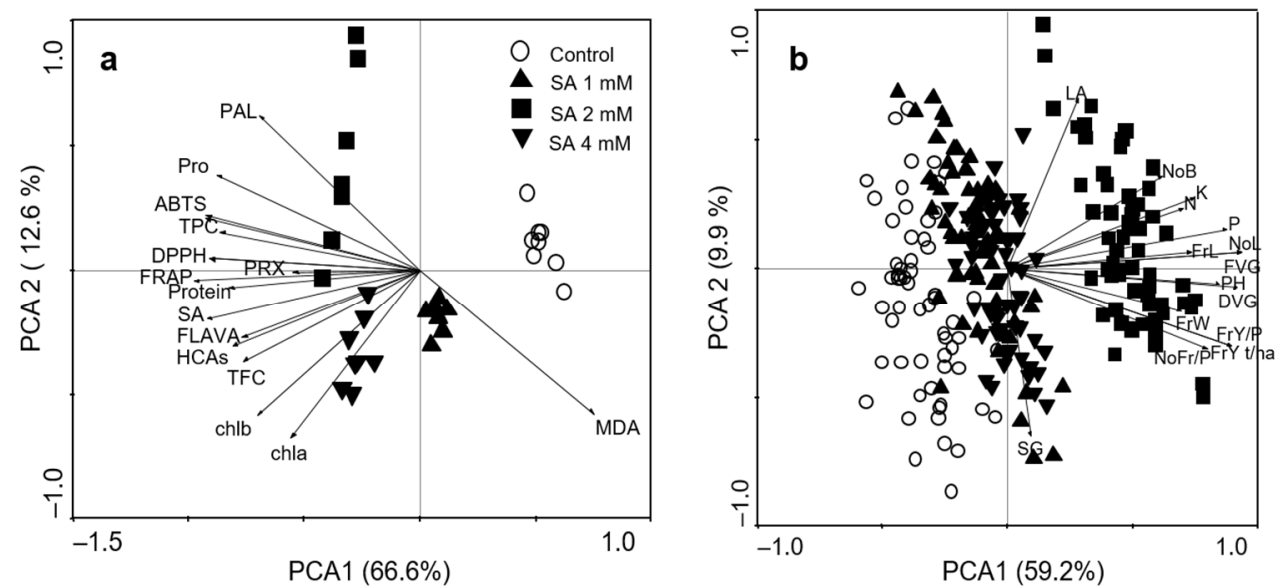

Figure 6. Principal component analysis (PCA) based on correlation matrix applied to biochemical (a) and agronomic (b) data sets. Each variable is represented by an arrow, and the longer its length, the greater its contribution to a given component. The angle between arrows indicates the degree of correlation among variables-the smaller the angle, the higher the correlation. Abbreviations: DVG, dry vegetative growth; FVG, fresh vegetative growth; FrL, fruit length; FrW, fruit weight, FrY $t$ /ha, fruit yield tonnes per hectare; FrY / P, fruit yield per plant; LA, leaf area; LRWC, leaf relative water content; MSI, membrane stability index; NoB, number of branches; NoFr/P, number of fruit per plant; NoL, number of leaves; PH, plant height; SG, stem girth.

As regards agronomic yield parameters, PCA plot revealed a clear separation between 2 mM SA-treated plants and the others due to PC1, which accounted for $59.2 \%$ of the total variance (Figure $6 \mathrm{~b}$ ). The main differences between $2 \mathrm{mM}$ SA-treated plants and the other groups, which were tightly clustered together, were associated with fresh and dry vegetative biomass; growth attributes (number of leaves, plant height, number of branches); foliar levels of N, P, and K; and fruit quality biometric traits and yield.

\section{Discussion}

Our study results revealed that foliar application of low doses of SA not only improved okra growth by promoting the synthesis of chlorophylls, proteins, and yield-contributing parameters but also induced phenol metabolism and the accumulation of antioxidant phenolic compounds.

The growth-stimulatory effects induced by low concentrations of SA have also been reported in other crops such as maize [15], wheat [37], tomato [38], and mustard [39], among others (for review see [11]), particularly under stress conditions [13]. These studies revealed that the SA-induced growth-promoting effects are associated with the SA-mediated activation of photosynthetic capacity, including the net photosynthetic rate, carboxylation efficiency, and chlorophyll content, as well as nitrate reductase activity, resulting in enhanced crop yield. In the current study, we also observed a significant increase in the levels of chlorophylls and proteins as well as an improvement of different agronomic yield parameters, mainly when okra plants were treated with $2 \mathrm{mM}$ of SA. These results suggest a positive role in the regulation of photosynthetic efficiency, as well as in the availability of assimilates, leading to better crop performance. In addition, our PCA results showed strong correlations between the levels of chlorophylls and proteins with the endogenous content of SA. Interestingly, the foliar content of free SA in SA-treated plants was quite similar (ranging from 220 to $255 \mu \mathrm{g} \mathrm{g}^{-1} \mathrm{FW}$ ), which raises the question about the source of these increased hormone levels ( $\sim 10$-fold higher than controls). By using radioactive SA solutions, de novo synthesis of SA has been reported in pea seedlings grown from ${ }^{3}$ H-labeled SA-presoaked seeds [40]. Moreover, the permeability of plant cuticles to SA has been described to be very low at pHs above 3.0, although the methylated form of SA (i.e., methyl salicylate) showed a high cuticular permeability [41]. Although the mechanism involved in the accumulation of SA in SA-sprayed plants has not been fully expounded [42], 
pronounced changes in free, bound, and/or methylated SA levels have been described in different SA-treated plants $[20,43,44]$. Altogether these results point to a fine-tuned control of the levels of free SA and its derivatives, which is of crucial importance to allow an appropriate cellular response [45].

On the other hand, it is well-known that SA plays a key role in maintaining cellular redox homeostasis through the regulation of antioxidative pathways, thereby preventing oxidative damage to lipids and other macromolecules [46-48]. Here, we observed a reduction in lipid peroxidation, measured as MDA, as well as an increase in total antioxidant capacity in SA-treated plants. Indeed, high-to-moderate correlations between MDA, TAC, and endogenous SA were also found, suggesting that the strengthening of antioxidant capacity induced by SA eventually provides oxidative protection and can, therefore, be beneficial to plant growth and yield. Contrarily to MDA, the foliar accumulation of the stress-metabolite proline was closely associated with TAC, phenolics, proteins, and PAL. In this way, there is cumulative evidence for the existence of a connection between primary and secondary metabolism that couples the accumulation of proline with the biosynthesis of phenylpropanoids through the pentose phosphate pathway $[49,50]$. Furthermore, a positive link between increased proline content and TPC was also demonstrated in transgenic tobacco plants over-producing proline [51]. The results presented in this work also suggest the association between proline levels, the stimulation of PAL, and the increased accumulation of phenolics in response to SA treatment. In addition, our data also revealed that the increases in TPC and in those of the phenolic families analyzed follow a trend similar to that observed for antioxidant capacity in SA-treated plants. Many flavonoids and hydroxycinnamic acids are recognized to be effective antioxidants due to their ability to scavenge ROS, chelate metals, and quench lipid peroxidation $[52,53]$. Thus, the observed pattern of antioxidant capacity could be ascribed, at least in part, to these phenolic compounds.

Flavonoids and hydroxycinnamic acids derive from the phenylpropanoid pathway in which the enzyme PAL plays a pivotal role [54]. As a gateway enzyme in the regulation of carbon flux from primary to secondary metabolism, both PAL activity and the genes encoding PAL are strongly regulated by both developmental and environmental cues [55]. Here, PAL activity in okra leaf tissues increased in response to SA, more notably in $2 \mathrm{mM}$ SA-treated plants. These results are in agreement with previous findings showing that SA induces PAL enzymatic activity/gene expression and increases phenolic accumulation, resulting in higher antioxidant properties [19,43,56-58].

Apart from this direct involvement in the control of ROS levels in cells, phenolics can also scavenge $\mathrm{H}_{2} \mathrm{O}_{2}$ by an indirect mechanism in which the enzyme peroxidase and ascorbic acid are also involved $[59,60]$. Here, the rise in Prx activity in response to SA treatment could lead to deactivation of ROS by the Prx/phenol redox cycle, in which phenolic compounds act as electron donors and the oxidized phenol product is regenerated by ascorbate [59]. Therefore, it seems to be plausible that SA treatments could prepare okra plants to control ROS homeostasis by increasing the levels of both phenolics and Prx activity in leaf tissues.

Thus, the beneficial effect promoted by foliar SA application seems to be related with the strengthening of the antioxidant capacity, mainly by increasing phenolics through the induction of PAL and Prx activities, which further resulted in higher photosynthetic capacity and higher protein content.

Similarly, field agronomic data also revealed that SA treatment, particularly the dose of 2 mM SA, significantly enhanced okra-yield-associated parameters related with vegetative growth attributes, biomass, macro nutrient foliar levels, and fruit quality and yield. Moreover, the improvement in agronomic attributes seems to be related with higher antioxidant activity estimated by membrane stability index, which points to a connection between antioxidant system robustness and crop growth and productivity. 


\section{Conclusions}

The current study clearly demonstrated that it is feasible to substantially enhance okra crop overall performance and foliar nutritional quality in terms of protein content, antioxidant capacity, and the accumulation of secondary metabolites (i.e., total phenolics, total flavonoids, flavanols, and hydroxycinnamic acids) by foliar spraying with SA. The beneficial impacts of SA treatment seem to be related to its direct effects on the enhancement of the foliar antioxidant capacity. Thus, the strengthening of antioxidant activity ameliorated lipid peroxidation damage, which further resulted in higher photosynthesis capacity leading to better yield performance. Therefore, foliar application of SA seems to be a truly potent and cost-effective approach to enhance okra crop quality and yield.

Supplementary Materials: The following are available online at https:/ /www.mdpi.com/article/10 .3390/agronomy12010168/s1, Figure S1: Effect of foliar SA applications on total antioxidant activities in leaves of 45-day-old okra plants using gallic acid as standard. A, ABTS ${ }^{\bullet+}$ - radical scavenging activity; B, DPPH ${ }^{\bullet}$-radical scavenging activity; Table S1: Pearson's correlation coefficients among biochemical data measured in leaves of 45-day-old okra plants. Statistical significance was represented as asterisks $\left({ }^{*} p \leq 0.05 ; * * \leq 0.01\right)$. Table S2: Effect of foliar SA applications on agronomic vegetative growth parameters as well as fruit-yield-related attributes. The data are means $\pm \mathrm{SE}$ from $n=60$ from two field experiments carried out on two different growing seasons. Different letters in the same row indicate significant difference at $p<0.05$ (Tukey's HSD post hoc test). Table S3: Effect of foliar SA applications on agronomic vegetative growth parameters as well as fruit-yield-related attributes in the two different growing seasons (S1 and S2). The data are means $\pm \mathrm{SE}$ from $n=30$. Different letters in the same row indicate significant difference at $p \leq 0.05$ (Tukey's HSD post hoc test). Results of one-way ANOVA test showing $F$-values and level of significance for selected yield parameters are also indicated. Level of significance: ${ }^{* * *} p \leq 0.001$; NS $=$ not significant. Table S4: Pearson's correlation coefficients among agronomic-yield-associated traits. Statistical significance was represented as asterisks ( $\left.p \leq 0.05 ;{ }^{* *} p \leq 0.01\right)$.

Author Contributions: Conceptualization, S.M.Y., A.A.C. and M.A.F.; methodology, S.M.Y. and A.L.O.; formal analysis, S.M.Y. and M.A.F.; investigation, S.M.Y. and A.L.-O.; resources, A.A.C.; writingoriginal draft preparation, S.M.Y.; writing-review and editing, A.A.C. and M.A.F.; visualization, M.A.F.; supervision, M.A.F.; project administration, S.M.Y. and A.A.C.; funding acquisition, S.M.Y. and A.L.-O. All authors have read and agreed to the published version of the manuscript.

Funding: This research is part of a scientific mission funded from the Egyptian cultural affairs and mission sector. A.L.-O. holds a grant from the MECD (AP2012-2559).

Data Availability Statement: The data presented in this study are available on request from the corresponding author.

Acknowledgments: We thank Hui Wang (NERC/Centre for Ecology and Hydrology-Oxford, Oxford, UK) for the SA biosensor strain Acinetobacter sp. ADPWH_lux. Part of this work was carried out at the Instituto de Biotecnologia Vegetal-UPCT.

Conflicts of Interest: The authors declare no conflict of interest. The funders had no role in the design of the study; in the collection, analyses, or interpretation of data; in the writing of the manuscript; or in the decision to publish the results.

\section{References}

1. Drewnowski, A. 50 Foods for Healthier People and a Healthier Planet; World Wildlife Foundation, Knorr Foods, 2019. Available online: https:/ / www.wwf.org.uk/sites/default/files/2019-02/Knorr_Future_50_Report_FINAL_Online.pdf (accessed on 20 December 2021).

2. $\quad$ Elkhalifa, A.E.O.; Alshammari, E.; Adnan, M.; Alcantara, J.C.; Awadelkareem, A.M.; Eltoum, N.E.; Mehmood, K.; Panda, B.P.; Ashraf, S.A. Okra (Abelmoschus esculentus) as a potential dietary medicine with nutraceutical importance for sustainable health applications. Molecules 2021, 26, 696. [CrossRef]

3. Lamont, W.J. Okra-A versatile vegetable crop. Horttechnology 1999, 9, 179-184. [CrossRef]

4. Islam, M.T. Phytochemical information and pharmacological activities of Okra (Abelmoschus esculentus): A literature-based review. Phyther. Res. 2019, 33, 72-80. [CrossRef] 
5. Camciuc, M.; Deplagne, M.; Vilarem, G.; Gaset, A. Okra-Abelmoschus esculentus L. (Moench.) a crop with economic potential for set aside acreage in France. Ind. Crops Prod. 1998, 7, 257-264. [CrossRef]

6. Moosavi, S.A.; Aghaalikhani, M.; Ghobadian, B.; Fayyazi, E. Okra: A potential future bioenergy crop in Iran. Renew. Sustain. Energy Rev. 2018, 93, 517-524. [CrossRef]

7. FAOSTAT Food and Agriculture Organization of the United Nations. FAOSTAT Statistical Database: 2018; FAO: Rome, Italy, 2018.

8. Savvides, A.; Ali, S.; Tester, M.; Fotopoulos, V. Chemical priming of plants against multiple abiotic stresses: Mission possible? Trends Plant Sci. 2016, 21, 329-340. [CrossRef]

9. Rhaman, M.S.; Imran, S.; Rauf, F.; Khatun, M.; Baskin, C.C.; Murata, Y.; Hasanuzzaman, M. Seed priming with phytohormones: An effective approach for the mitigation of abiotic stress. Plants 2020, 10, 37. [CrossRef]

10. Vlot, A.C.; Dempsey, D.A.; Klessig, D.F. Salicylic Acid, a multifaceted hormone to combat disease. Annu. Rev. Phytopathol. 2009, 47, 177-206. [CrossRef]

11. Rivas-San Vicente, M.; Plasencia, J. Salicylic acid beyond defence: Its role in plant growth and development. J. Exp. Bot. 2011, 62, 3321-3338. [CrossRef]

12. Chen, J.; Clinton, M.; Qi, G.; Wang, D.; Liu, F.; Qing Fu, Z. Reprogramming and remodeling: Transcriptional and epigenetic regulation of salicylic acid-mediated plant defense. J. Exp. Bot. 2020, 71, 5256-5268. [CrossRef]

13. Khan, M.I.R.; Fatma, M.; Per, T.S.; Anjum, N.A.; Khan, N.A. Salicylic acid-induced abiotic stress tolerance and underlying mechanisms in plants. Front. Plant Sci. 2015, 6, 462. [CrossRef]

14. Liu, S.; Dong, Y.; Xu, L.; Kong, J. Effects of foliar applications of nitric oxide and salicylic acid on salt-induced changes in photosynthesis and antioxidative metabolism of cotton seedlings. Plant Growth Regul. 2014, 73, 67-78. [CrossRef]

15. Tahjib-Ul-Arif, M.; Siddiqui, M.N.; Sohag, A.A.M.; Sakil, M.A.; Rahman, M.M.; Polash, M.A.S.; Mostofa, M.G.; Tran, L.-S.P. Salicylic acid-mediated enhancement of photosynthesis attributes and antioxidant capacity contributes to yield improvement of maize plants under salt stress. J. Plant Growth Regul. 2018, 37, 1318-1330. [CrossRef]

16. Gunes, A.; Inal, A.; Alpaslan, M.; Eraslan, F.; Bagci, E.G.; Cicek, N. Salicylic acid induced changes on some physiological parameters symptomatic for oxidative stress and mineral nutrition in maize (Zea mays L.) grown under salinity. J. Plant Physiol. 2007, 164, 728-736. [CrossRef] [PubMed]

17. Csiszár, J.; Brunner, S.; Horváth, E.; Bela, K.; Ködmön, P.; Riyazuddin, R.; Gallé, Á.; Hurton, Á.; Papdi, C.; Szabados, L.; et al. Exogenously applied salicylic acid maintains redox homeostasis in salt-stressed Arabidopsis gr1 mutants expressing cytosolic roGFP1. Plant Growth Regul. 2018, 86, 181-194. [CrossRef]

18. Kiddle, G.A.; Doughty, K.J.; Wallsgrove, R.M. Salicylic acid-induced accumulation of glucosinolates in oilseed rape (Brassica napus L.) leaves. J. Exp. Bot. 1994, 45, 1343-1346. [CrossRef]

19. López-Orenes, A.; Martínez-Moreno, J.M.; Calderón, A.A.; Ferrer, M.A. Changes in phenolic metabolism in salicylic acid-treated shoots of Cistus heterophyllus. Plant Cell Tissue Organ Cult. 2013, 113, 417-427. [CrossRef]

20. López-Orenes, A.; Martínez-Pérez, A.; Calderón, A.A.; Ferrer, M.A. Pb-induced responses in Zygophyllum fabago plants are organ-dependent and modulated by salicylic acid. Plant Physiol. Biochem. 2014, 84, 57-66. [CrossRef] [PubMed]

21. Pérez-Tortosa, V.; López-Orenes, A.; Martínez-Pérez, A.; Ferrer, M.A.; Calderón, A.A. Antioxidant activity and rosmarinic acid changes in salicylic acid-treated Thymus membranaceus shoots. Food Chem. 2012, 130, 362-369. [CrossRef]

22. Ali, B. Salicylic acid: An efficient elicitor of secondary metabolite production in plants. Biocatal. Agric. Biotechnol. 2021, 31, 101884. [CrossRef]

23. Vauzour, D.; Rodriguez-Mateos, A.; Corona, G.; Oruna-Concha, M.J.; Spencer, J.P.E. Polyphenols and Human Health: Prevention of Disease and Mechanisms of Action. Nutrients 2010, 2, 1106-1131. [CrossRef]

24. Arora, I.; Sharma, M.; Sun, L.Y.; Tollefsbol, T.O. The Epigenetic Link between Polyphenols, Aging and Age-Related Diseases. Genes 2020, 11, 1094. [CrossRef]

25. MALR Egyptian Ministry of Agriculture and Land Reclamation. Agricultural Statistics Bulletin. Part Two Summer and Autumn Crops 2018/2019; Department of Economic Affairs: Cairo, Egypt, 2020.

26. Hoagland, D.R.; Arnon, D.I. The water-culture method for growing plants without soil. Calif. Agric. Exp. Stn. Circ. 1950, 347, $1-32$.

27. Hassan, A.A. Okra Production. Extension Bulletin, Care International- Egypt, USAID. 2005. Available online: https://www. mediafire.com/file/39120zxxm28v2yr/2157.pdf/file (accessed on 20 December 2021). (In Arabic).

28. López-Orenes, A.; Bueso, M.C.; Conesa, H.; Calderón, A.A.; Ferrer, M.A. Seasonal ionomic and metabolic changes in Aleppo pines growing on mine tailings under Mediterranean semi-arid climate. Sci. Total Environ. 2018, 637-638, 625-635. [CrossRef] [PubMed]

29. Lichtenthaler, H.K.; Wellburn, A.R. Determinations of total carotenoids and chlorophylls a and b of leaf extracts in different solvents. Biochem. Soc. Trans. 1983, 11, 591-592. [CrossRef]

30. López-Arnaldos, T.; Muñoz, R.; Ferrer, M.A.; Calderón, A.A. Changes in phenol content during strawberry (Fragaria x ananassa, cv. Chandler) callus culture. Physiol. Plant. 2001, 113, 315-322. [CrossRef] [PubMed]

31. Huang, W.E.; Huang, L.; Preston, G.M.; Naylor, M.; Carr, J.P.; Li, Y.; Singer, A.C.; Whiteley, A.S.; Wang, H. Quantitative in situ assay of salicylic acid in tobacco leaves using a genetically modified biosensor strain of Acinetobacter sp. ADP1. Plant J. 2006, 46, 1073-1083. [CrossRef] 
32. Huang, W.E.; Wang, H.; Zheng, H.; Huang, L.; Singer, A.C.; Thompson, I.; Whiteley, A.S. Chromosomally located gene fusions constructed in Acinetobacter sp ADP1 for the detection of salicylate. Environ. Microbiol. 2005, 7, 1339-1348. [CrossRef] [PubMed]

33. Defraia, C.T.; Schmelz, E.A.; Mou, Z. A rapid biosensor-based method for quantification of free and glucose-conjugated salicylic acid. Plant Methods 2008, 4, 28. [CrossRef] [PubMed]

34. AOAC. Official Methods of Analysis, 17th ed.; The Association of Official Analytical Chemists: Gaithersburg, MD, USA, 2000; ISBN 0935584870 .

35. López-Orenes, A.; Bueso, M.C.; Conesa, H.M.; Calderón, A.A.; Ferrer, M.A. Seasonal changes in antioxidative/oxidative profile of mining and non-mining populations of Syrian beancaper as determined by soil conditions. Sci. Total Environ. 2017, 575, 437-447. [CrossRef]

36. Premachandra, G.S.; Saneoka, H.; Ogata, S. Cell membrane stability, an indicator of drought tolerance, as affected by applied nitrogen in soyabean. J. Agric. Sci. 1990, 115, 63-66. [CrossRef]

37. Sharma, M.; Gupta, S.K.; Majumder, B.; Maurya, V.K.; Deeba, F.; Alam, A.; Pandey, V. Salicylic acid mediated growth, physiological and proteomic responses in two wheat varieties under drought stress. J. Proteom. 2017, 163, 28-51. [CrossRef]

38. Stevens, J.; Senaratna, T.; Sivasithamparam, K. Salicylic acid induces salinity tolerance in tomato (Lycopersicon esculentum cv. Roma): Associated changes in gas exchange, water relations and membrane stabilisation. Plant Growth Regul. 2006, 49, 77-83. [CrossRef]

39. Fariduddin, Q.; Hayat, S.; Ahmad, A. Salicylic Acid Influences Net Photosynthetic Rate, Carboxylation Efficiency, Nitrate Reductase Activity, and Seed Yield in Brassica juncea. Photosynthetica 2003, 41, 281-284. [CrossRef]

40. Szalai, G.; Horgosi, S.; Soós, V.; Majláth, I.; Balázs, E.; Janda, T. Salicylic acid treatment of pea seeds induces its de novo synthesis. J. Plant Physiol. 2011, 168, 213-219. [CrossRef]

41. Niederl, S.; Kirsch, T.; Riederer, M.; Schreiber, L. Co-Permeability of 3H-Labeled Water and14C-Labeled Organic Acids across Isolated Plant Cuticles1. Plant Physiol. 1998, 116, 117-123. [CrossRef]

42. Maruri-López, I.; Aviles-Baltazar, N.Y.; Buchala, A.; Serrano, M. Intra and Extracellular Journey of the Phytohormone Salicylic Acid. Front. Plant Sci. 2019, 10, 423. [CrossRef] [PubMed]

43. Gondor, O.K.; Janda, T.; Soós, V.; Pál, M.; Majláth, I.; Adak, M.K.; Balázs, E.; Szalai, G. Salicylic Acid Induction of Flavonoid Biosynthesis Pathways in Wheat Varies by Treatment. Front. Plant Sci. 2016, 7, 1447. [CrossRef] [PubMed]

44. Deng, B.; Wang, W.; Ruan, C.; Deng, L.; Yao, S.; Zeng, K. Involvement of CsWRKY70 in salicylic acid-induced citrus fruit resistance against Penicillium digitatum. Hortic. Res. 2020, 7, 157. [CrossRef] [PubMed]

45. Dempsey, D.A.; Vlot, A.C.; Wildermuth, M.C.; Klessig, D.F. Salicylic Acid Biosynthesis and Metabolism. Arab. B 2011, 9, e0156. [CrossRef]

46. Mateo, A.; Funck, D.; Mühlenbock, P.; Kular, B.; Mullineaux, P.M.; Karpinski, S. Controlled levels of salicylic acid are required for optimal photosynthesis and redox homeostasis. J. Exp. Bot. 2006, 57, 1795-1807. [CrossRef]

47. Herrera-Vásquez, A.; Salinas, P.; Holuigue, L. Salicylic acid and reactive oxygen species interplay in the transcriptional control of defense genes expression. Front. Plant Sci. 2015, 6, 1-9. [CrossRef]

48. Bidabadi, S.S.; Mahmood, M.; Baninasab, B.; Ghobadi, C. Influence of salicylic acid on morphological and physiological responses of banana (Musa acuminata cv. "Berangan", AAA) shoot tips to in vitro water stress induced by polyethylene glycol. Plant Omics 2012, 5, 33-39.

49. Shetty, K. Role of proline-linked pentose phosphate pathway in biosynthesis of plant phenolics for functional food and environmental applications: A review. Process Biochem. 2004, 39, 789-804. [CrossRef]

50. Caretto, S.; Linsalata, V.; Colella, G.; Mita, G.; Lattanzio, V. Carbon Fluxes between Primary Metabolism and Phenolic Pathway in Plant Tissues under Stress. Int. J. Mol. Sci. 2015, 16, 26378-26394. [CrossRef] [PubMed]

51. Silva, F.L.B.; Vieira, L.G.E.; Ribas, A.F.; Moro, A.L.; Neris, D.M.; Pacheco, A.C. Proline accumulation induces the production of total phenolics in transgenic tobacco plants under water deficit without increasing the G6PDH activity. Theor. Exp. Plant Physiol. 2018, 30, 251-260. [CrossRef]

52. Rice-Evans, C.; Miller, N.; Paganga, G. Antioxidant properties of phenolic compounds. Trends Plant Sci. 1997, 2, 152-159. [CrossRef]

53. Agati, G.; Azzarello, E.; Pollastri, S.; Tattini, M. Flavonoids as antioxidants in plants: Location and functional significance. Plant Sci. 2012, 196, 67-76. [CrossRef] [PubMed]

54. Boudet, A.-M. Evolution and current status of research in phenolic compounds. Phytochemistry 2007, 68, 2722-2735. [CrossRef]

55. Barros, J.; Dixon, R.A. Plant Phenylalanine/Tyrosine Ammonia-lyases. Trends Plant Sci. 2020, 25, 66-79. [CrossRef]

56. Wen, P.-F.; Chen, J.-Y.; Kong, W.-F.; Pan, Q.-H.; Wan, S.-B.; Huang, W.-D. Salicylic acid induced the expression of phenylalanine ammonia-lyase gene in grape berry. Plant Sci. 2005, 169, 928-934. [CrossRef]

57. Shaki, F.; Maboud, H.E.; Niknam, V. Growth enhancement and salt tolerance of Safflower (Carthamus tinctorius L.), by salicylic acid. Curr. Plant Biol. 2018, 13, 16-22. [CrossRef]

58. Chavoushi, M.; Najafi, F.; Salimi, A.; Angaji, S.A. Effect of salicylic acid and sodium nitroprusside on growth parameters, photosynthetic pigments and secondary metabolites of safflower under drought stress. Sci. Hortic. 2020, 259, 108823. [CrossRef] 
59. Yamasaki, H.; Sakihama, Y.; Ikehara, N. Flavonoid-Peroxidase Reaction as a Detoxification Mechanism of Plant Cells against H2O2. Plant Physiol. 1997, 115, 1405-1412. [CrossRef] [PubMed]

60. Ferreres, F.; Figueiredo, R.; Bettencourt, S.; Carqueijeiro, I.; Oliveira, J.; Gil-Izquierdo, A.; Pereira, D.M.; Valentão, P.; Andrade, P.B.; Duarte, P.; et al. Identification of phenolic compounds in isolated vacuoles of the medicinal plant Catharanthus roseus and their interaction with vacuolar class III peroxidase: $\mathrm{An}_{2} \mathrm{O}_{2}$ affair? J. Exp. Bot. 2011, 62, 2841-2854. [CrossRef] [PubMed] 